\title{
Intensificação e prolongamento da jornada de trabalho nas indústrias de abate e processamento de carnes e seus impactos na saúde dos trabalhadores ${ }^{1}$
}

\author{
Márcia Luíza Pit Dal Magro², Maria Chalfin Coutinho³, Josep Maria Blanch \\ ${ }^{4}$ e Carmen Leontina Ojeda Ocampo Moré ${ }^{5}$
}

Universidade Comunitária da Região de Chapecó (Chapecó, SC), Universidade Federal de Santa Catarina (Florianópolis, SC), Universidad Autónoma de Barcelona (Barcelona, ES)

As indústrias de abate e processamento de carnes vêm assumindo grande importância econômica no cenário nacional, entretanto, as difíceis condições de trabalho nesse setor ocasionam o adoecimento de muitos trabalhadores. O objetivo deste estudo foi identificar as características do trabalho nas agroindústrias do estado de Santa Catarina e analisar a relação dessas com a saúde dos trabalhadores. Esta pesquisa é de natureza qualitativa e, por sua vez, um estudo descritivo exploratório. Os instrumentos utilizados para o levantamento de informações foram entrevistas semiestruturadas realizadas com 17 trabalhadores e 14 profissionais de saúde. A entrevista foi subsidiada pelos registros de diário de campo decorrentes de observação participante. Por meio deste estudo observou-se que, apesar das tentativas de fiscalização e regulamentação das atividades laborais no setor agroindustrial, vem ocorrendo um processo de intensificação e prolongamento da jornada de trabalho nesse contexto, aspectos que são as principais características desse trabalho na região estudada. Nesse sentido, se destacou uma estreita relação entre a atividade produtiva nas indústrias de abate e processamento de carnes e o adoecimento dos trabalhadores do setor.

Palavras-chave: Indústrias de abate e processamento de carnes, Intensificação do trabalho, Prolongamento da jornada laboral, Saúde do trabalhador.

Intensification and prolongation of the working journey in industries of slaughter and meat processing and their impact on workers' health

Industries of slaughter and meat processing have assumed great economic importance in the national scene, however, the hard working conditions in those sectors cause the illness of many workers. This study's aim was to identify the characteristics of work in the agro-industries of the state of Santa Catarina and to analyze the relationship between these organizations and their workers' health. This research is qualitative in nature and a descriptive exploratory study. The instruments used for collecting information were records of a field diary, made in the course of participant observation and also semi-structured interviews with 17 workers and 14 health professionals. As a result of the study, it was observed that in despite of the attempts of inspection and regulation of labor activities in the agro-industrial sector, there has been a process of intensification and prolongation of the working journey, which are the main characteristics of that kind of work in the studied region. Thus, a close relationship became clear between productive activities in slaughter and meat processing industries and illness among workers of the sector.

Keywords: Slaughter and meat processing industries, Intensification of work, Prolongation of the working journey, Workers' health.

1 Projeto financiado pela CAPES por meio de bolsa PDEE, e aprovado pelo Comitê de Ética em Pesquisa com Seres Humanos (CEPSH) da Universidade Federal de Santa Catarina (parecer n. 473/12).

2 Professora do Programa de Pós-Graduação em Políticas Sociais e Dinâmicas Regionais da Universidade Comunitária da Região de Chapecó - UNOCHAPECÓ.

3 Professora do Programa de Pós-Graduação em Psicologia da Universidade Federal de Santa Catarina - UFSC. Bolsista produtividade pelo CNPq.

4 Professor do Departamento Psicología Social. Facultad de Psicología, Universidad Autónoma de Barcelona - UAB.

5 Professora do Programa de Pós-Graduação em Psicologia da Universidade Federal de Santa Catarina - UFSC. Bolsista produtividade pelo $\mathrm{CNPq}$. 


\section{Introdução}

As indústrias de abate e processamento de carnes, também conhecidas como agroindústrias, vêm assumindo grande importância econômica no cenário nacional. Isso é demonstrado pelo relatório da Organização das Nações Unidas para Agricultura e Alimentação (CEPAL/FAO, 2009), o qual aponta o Brasil como terceiro maior produtor de aves do mundo e como o maior exportador, detendo um terço do comércio global. De acordo com Dalla Costa e Souza-Santos (2009), a recente fusão entre duas grandes empresas do setor (Sadia e Perdigão) deu origem a uma das maiores companhias de alimentos do mundo e a maior empregadora do país, com mais de 100 mil funcionários.

Nesse contexto, o estado de Santa Catarina liderava, até 2008, a produção e exportação de aves no Brasil (Reche \& Sugai, 2008), cenário em que o município de Chapecó-SC, local onde foi desenvolvida a presente pesquisa, ocupa lugar de destaque. Tal município também é considerado, segundo os autores anteriormente referidos, o mais importante centro agroindustrial do país, o que lhe rendeu o título de capital brasileira da agroindústria. Atualmente, Chapecó sedia grandes empresas do setor como a Brasil Foods que juntamente a agroindústrias de menor porte empregam aproximadamente $18 \%$ da força de trabalho ocupada do município de acordo com os dados do Instituto Brasileiro de Geografia e Estatística - IBGE (2009).

A organização do trabalho nas indústrias de abate e processamento de carnes mescla características do padrão taylorista fordista e do modelo japonês, sendo caracterizada por funções altamente rotinizadas e repetitivas, intenso ritmo de trabalho e inúmeras formas de vigilância e controle do trabalhador. Devido aos riscos desse contexto laboral, a relação entre as atividades em linhas de produção e agravos em saúde, especialmente as LER/DORT ${ }^{6}$, já são amplamente reconhecidas e estudadas ${ }^{7}$, assim como a manifestação dessas doenças especificamente nos trabalhadores das indústrias de abate e processamento de carnes ${ }^{8}$. Nesse sentido, vale destacar que recentemente foram divulgados nos meios de comunicação os resultados de uma pesquisa que mapeou o perfil dos agravos à saúde que atingiram os trabalhadores de Santa Catarina no período de 2005 a 2011. Em tal estudo indica que o número de trabalhadores afastados por motivos de saúde no estado é $48 \%$ maior que a média nacional e que o setor econômico que mais registrou afastamentos foi o de abate e processamento de carnes (Procuradoria Regional do Trabalho, 2013). Assim, na região estudada se observa um grande fluxo de trabalhadores e ex-trabalhadores desse setor aos serviços de saúde em busca de assistência, com queixas relacionadas ao trabalho.

Em função das dificuldades desses contextos laborais bem como do reconhecimento dos agravos à saúde dos trabalhadores decorrentes, vêm sendo adotadas medidas para melhorarem as condições de trabalho neste setor. Isso pode ser observado na instituição da Norma Regulamentadora 36 (Ministério do Trabalho e Emprego, 2013), que reconhece diversos riscos específicos nas atividades dessas indústrias de alimentos e propõe formas de controle e eliminação dos mesmos.

Tendo em vista a importância de subsidiar o atual debate em torno dos riscos e da fiscalização do trabalho no setor agroindustrial, o objetivo do presente artigo consiste em identificar as características do trabalho nas agroindústrias do estado de Santa Catarina e a relação destas com a saúde dos trabalhadores do setor.

6 Lesões por Esforços Repetitivos também denominadas Doenças Osteomusculares Relacionadas ao Trabalho.

7 Como exemplos de estudos que estabelecem esta relação se pode citar Ghisleni e Merlo (2005), Picoloto e Silveira (2008), Assunção e Vilela (2009) e Fernandes, Assunção e Carvalho (2010).

8 Sato e Lacaz (2000), Brasil (2001), Neli (2006), Sardá, Ruiz e Kirtschig (2009), Araújo e Gosling (2008), Serranheira, Uva e Espírito-Santo (2009), Sardá Júnior; Kupek; Cruz; Bartilotti e Cherem (2009); Sardá Júnior, Kupek e Cruz (2009), Santos (2011), Ministério do Trabalho e Emprego (2013). 


\section{Método}

Esta pesquisa se caracteriza por ser de natureza qualitativa e por sua vez, um estudo descritivo exploratório, sendo que os resultados apresentados fazem parte de um estudo mais abrangente? Fizeram parte da investigação, dois grupos de participantes, sendo um deles constituído por dezessete trabalhadores de três grandes agroindústrias da região. Já o outro grupo foi composto por catorze profissionais de saúde que atuavam na rede pública, ao qual se agregou também um ex-trabalhador da agroindústria e membro de sindicato que vinha buscando representar a categoria. Cabe destacar que para a produção do presente artigo e visando melhor responder ao seu objetivo priorizou-se o relato do primeiro grupo, sendo também mencionado o relato feito pelos participantes do segundo grupo somente com o intuito de melhor subsidiar a compreensão da temática abordada.

Os critérios de escolha dos trabalhadores que concederam as entrevistas foram: 1) que esses fossem homens e mulheres com idade mínima de dezoito anos, que atuassem nas linhas de produção de uma das grandes agroindústrias da região, mantendo vínculo de trabalho com elas no momento da pesquisa; 2) que os trabalhadores participantes apresentassem queixas em saúde relacionadas à sua atividade profissional. Assim, esses entrevistados faziam uso esporádico ou contínuo de serviços de saúde da rede pública, em virtude disso, serão denominados neste trabalho como trabalhadores usuários. Em relação ao grupo de profissionais de saúde, os critérios foram: 1) que esses estivessem vinculados a serviços de saúde que se destacavam no percurso dos trabalhadores usuários pela rede. $\mathrm{O}$ trabalho de campo teve início após submissão e aprovação pelo Comitê de Ética em Pesquisa com Seres Humanos (CEPSH) da Universidade Federal de Santa Catarina (parecer n. 473/12), de acordo com o que prevê a resolução 196/96 do Conselho Nacional de Saúde (Brasil, 1996).

Para atender aos objetivos propostos neste estudo, os instrumentos de pesquisa utilizados foram: a) registro de diário de campo decorrente da observação participante, b) as entrevistas semiestruturadas realizadas com os trabalhadores das agroindústrias e profissionais de saúde.

A organização e análise das informações na presente pesquisa se deram com base na Grounded Theory, ou Teoria Fundamentada nos Dados (Strauss \& Corbin, 2008). Essa metodologia de análise permite ao pesquisador combinar abordagens indutivas e dedutivas, ao investigar processos de uma mesma cena social sob várias perspectivas, visando a melhor compreensão do fenômeno estudado. Assim, o pesquisador pode integrar diferentes fontes de informações na construção da análise, que dão origem às categorias.

Do total de categorias que surgiram decorrentes da análise das informações, destacaram-se duas grandes categorias, que respondem ao objetivo proposto no presente artigo. A primeira delas é a "intensificação do trabalho", que caracteriza esse processo nas fábricas do setor agroindustrial e sua relação com a saúde dos trabalhadores. A segunda categoria abordada diz respeito à "extensão dos tempos de trabalho", na qual se discorre sobre a gestão dos mesmos no setor agroindustrial e alguns de seus impactos na saúde dos trabalhadores.

\section{A intensificação do trabalho no setor agroindustrial}

A intensidade do trabalho, segundo Dal Rosso (2006a), diz respeito ao dispêndio de energia do trabalhador para a realização do trabalho, ou como diz Marx (2002), implica a absorção da força de trabalho no processo produtivo. O conceito de intensidade se inscreve assim na dimensão

9 Este trabalho é parte de pesquisa de doutorado que teve como objetivo compreender como se produz a atenção à saúde dos trabalhadores das agroindústrias do estado de Santa Catarina. 
humana do trabalho, já que “... não se trata de examinar o desempenho das máquinas ou outras coisas quaisquer. Analisa-se o processo de trabalho, considerado em suas dimensões físicas, intelectuais e psíquicas" (Dal Rosso, 2006b, p. 54).

A intensificação do trabalho compreende uma ampliação quantitativa deste e/ou na sua melhora qualitativa, dentro da mesma unidade de tempo, em que, na expressão de Marx (2002, p. 468), é característico dos modos de produção capitalistas e tem se ampliado no contexto contemporâneo do capitalismo flexível como é registrado na literatura sobre tópicos como work intensity, overwork, work overload ou role overload (Duxbury, Lyons \& Higgins, 2008; Fairris, 2004; Galinsky et al, 2005; Gallie, 2005).

A partir dos relatos dos trabalhadores entrevistados, observou-se que vem ocorrendo um processo de intensificação do trabalho nas linhas de produção das indústrias de abate e processamento de carnes instaladas no oeste catarinense. Esta intensificação se evidenciou como um aspecto importante para a saúde dos trabalhadores do setor, e como um atravessamento significativo na demanda que os mesmos apresentam aos serviços da rede de saúde da região. Esse processo está relacionado a aspectos como as características dos processos de trabalho no interior das fábricas, às diferenças no desempenho entre os trabalhadores da linha de produção e ao quadro funcional incompleto.

Dentre as características do processo de trabalho no interior das agroindústrias, a "divisão pormenorizada do trabalho" ganha destaque, já que é elevada ao expoente máximo, estando presente nas diferentes funções deste contexto fabril. Os processos de intensificação do trabalho, segundo autores como Castel (1998) e Antunes (2003), são inerentes aos modos de produção atuais. Nesse sentido, o aumento da quantidade de trabalho que um sujeito pode realizar por meio de sua divisão pormenorizada é algo posto desde os primórdios do capitalismo industrial, como se pode observar na análise de Adam Smith (2003 - 1776). Este autor destaca que a fragmentação do trabalho leva ao aumento da destreza dos trabalhadores, à economia de tempo por não ter que mudar de uma atividade a outra, bem como favorece a invenção de máquinas que facilitam o trabalho.

No caso das agroindústrias estudadas, a divisão pormenorizada do trabalho faz com que cada trabalhador da linha de produção desempenhe uma atividade bastante específica e reduzida no processo produtivo, como expressa a trabalhadora 7: "O meu trabalho era pesar o peito de peru, a gente pesava ele na balança e jogava na mesa, aí tinham umas meninas que passavam ele no funil para colocar uma redinha, outros que amarravam a redinha lá na ponta e outros que selavam".

No processo de intensificação do trabalho que ocorre no setor agroindustrial, à divisão pormenorizada das tarefas alia-se o "uso das nórias"10, muito presentes nas linhas de produção dos frigoríficos. De acordo com Harvey (1992), essas esteiras transportadoras ajudam a evitar o deslocamento do trabalhador e auxiliam no controle do tempo dispensado à execução da atividade. Nesse sentido, as nórias são um símbolo destas indústrias, no entanto, representam apenas um dentre vários dispositivos de controle utilizados para sincronizar e ampliar o ritmo de trabalho no espaço fabril. Esse ritmo, por sua vez, é definido não pelo trabalhador, mas pela gerência, por meio do estabelecimento de "altas metas de produção", e assegurado pelo emprego da nória que permite o controle da velocidade com que o trabalho é realizado.

Os trabalhadores participantes da pesquisa descreveram dois níveis de metas de produção a serem cumpridas, um individual, relativo à quantidade de trabalho que cada funcionário deve realizar até ao final da jornada, e o outro coletivo, definido para o grupo de trabalhadores que atua em uma determinada célula de produção ou, como os entrevistados chamam, "mesa de trabalho".

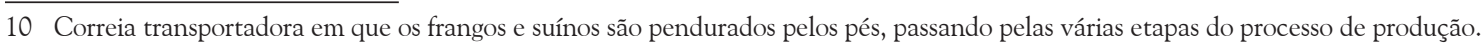


As altas metas de produção impostas aos trabalhadores do setor agroindustrial são muito mencionadas na literatura, como pode ser observado em trabalhos como de Neli (2006) e Santos (2011) ou ainda em fiscalizações do Ministério Público do Trabalho às empresas do setor, como expressa o Termo de Ajuste de Conduta (TAC), emitido pelo Ministério Público do Trabalho em 2011 (MPT, 2011). Isso vai ao encontro da realidade descrita pelos diferentes sujeitos que participaram desta pesquisa, como ilustra o relato da trabalhadora 10: "A gente tem um mínimo de coxas que tem que fazer que são cinco por minuto, mas dependendo da meta esse número aumenta". A trabalhadora 6 também aponta a definição das metas na realização da atividade: "tudo tem meta, tem que atingir uma meta de carne, uma meta de gordura, e um que não acompanhe estraga toda a mesa, tem que ser rápido”. Na direção do que aponta a entrevistada, "estragar a mesa" significa prejudicar a meta coletiva estabelecida para aquela célula de produção. Nesse sentido, os próprios trabalhadores cobram o cumprimento das metas entre si, colaborando para o controle do trabalho e fragilizando o coletivo dos trabalhadores.

Autores como Espíndola (1999) apontam como estas indústrias de alimentos têm investido no aumento das metas de trabalho individuais e coletivas para ampliar a produção. Nesse sentido, cabe mencionar o relato de um gerente de uma indústria do setor, entrevistado pelo referido autor:

Nós abatíamos 700 suínos/dia e, na sala de desmanche dos suínos 120 operários faziam o serviço em 10 horas. Aí eu pensei: vou pagar por produtividade. Em dois meses coloquei os 120 limpando retalhos e comecei a controlar. Daí eu encontrei funcionário que limpava 11 $\mathrm{kg} / \mathrm{h}$ e outros que limpavam $2 \mathrm{~kg} / \mathrm{h}$. A média geral era de $6 \mathrm{~kg} / \mathrm{h}$. [...] Daí eu cheguei para eles e disse: quando vocês chegarem a $25 \mathrm{~kg} / \mathrm{h}$ eu vou passar a pagar vocês com salário de primeira (um salário-mínimo e meio). Depois de quatro meses eles alcançaram a marca. Daí eu falei que iriam ganhar mais X se chegassem a $45 \mathrm{~kg} / \mathrm{h}$. Isto deu certo. (Espíndola, 1999, p. 48).

O relato acima remete ao mencionado por Neli (2006) sobre o aumento de produção no setor a partir da década de 1990 o qual não teria correspondido na mesma medida à criação de postos de trabalho. Esse aumento de produtividade de acordo com o referido autor é possibilitado por aspectos como a automatização de partes do processo produtivo, ao que Espíndola (1999) agrega a aceleração do ritmo de trabalho na linha, que caracteriza o processo de intensificação acima mencionado. Nesse sentido, a intensificação do trabalho possibilita o que Marx (2002) denomina como ganho de eficácia por meio da ampliação e condensação do trabalho.

O relato do profissional vinculado ao sindicato ${ }^{11}$ e à Associação dos Vitimados do Trabalho, o qual trabalhou por doze anos em uma agroindústria, também remete ao processo de intensificação: “... lá funciona assim, a pessoa produz dez quilos de linguiça a hora, no mês que vem eles colocam para doze quilos a hora. Se a pessoa consegue atingir essa meta, eles tentam subir. Então eu acho assim que, no geral, as empresas cobram muito do funcionário, muita meta, muita meta”.

Esse processo se assemelha à noção taylorista de ótimo dia de trabalho ${ }^{12}$, o qual, segundo Braverman (1981), representa a execução dats atividades em um ritmo que leva o trabalhador ao limite fisiológico, o que é expresso no relato da trabalhadora 14, quando diz: “... a gente vai

11 Vale retomar, conforme descrição presente no método, que este profissional estava vinculado a um sindicato que vinha na ocasião do trabalho de campo desta pesquisa, tentando representar os trabalhadores do setor a fim de fazer oposição ao então sindicato da categoria.

12 Esta expressão é cunhada por Taylor e diz respeito a "todo o trabalho que um operário pode fazer sem dano à sua saúde, em um ritmo que pode ser mantido através da sua vida de trabalho" (Braverman, 1981, p. 91). 
fazendo e eles vão largando (referindo-se as peças de carne na esteira), vão largando até que a gente aguenta". Os modos de trabalho no interior dessas fábricas remetem também a noção de "homem boi" cunhada por Taylor, em que o trabalhador é reduzido a um corpo forte e resistente ao qual se deve explorar o máximo da capacidade produtiva (Braverman, 1981).

A intensificação do trabalho por meio da divisão pormenorizada deste, aliada ao uso das nórias e as altas metas de produção geram ciclos de trabalho muito curtos. Segundo o Ministério do Trabalho e Emprego "considera-se alta repetitividade, tarefas em que ocorram ciclos de trabalho inferiores a 30 segundos ou permanência de 50\% do ciclo repetindo os mesmos gestos" (Ministério do Trabalho e Emprego, 2004, p. 13). Nesse sentido, o relato da trabalhadora 10 elucida a presença deste fator de risco: "Eu faço cinco coxas por minuto. Eu corto, tiro os ossos e depois refilo. Às vezes a gente faz mais, depende da meta".

Se calculado o ritmo de trabalho da entrevistada, chegamos à conclusão de que neste setor os trabalhadores dispõem de doze segundos para desossar cada coxa de frango, o que representa ao final de uma jornada de trabalho aproximadamente duas mil e quatrocentas coxas. Em atividades como a desossa, de acordo com Sardá, Ruiz e Kirstsching (2009), realizam-se em média cinco mil, cinquenta e dois movimentos por hora, o que corresponde a 84,2 movimentos por minuto.

A realidade descrita faz com que a repetitividade do trabalho seja um risco laboral muito importante nessas indústrias, sendo esse o fator de risco mais frequentemente associado ao aparecimento das LER/DORT, como pode ser observado em documentos sobre doenças relacionadas ao trabalho (Brasil, OPAS, 2001). Nesse sentido, cabe destacar que dezesseis entre os dezessete trabalhadores entrevistados fazem menção às dores osteomusculares crônicas ${ }^{13}$ nos membros superiores, as quais são apontadas por Assunção e Vilela (2009) como preditoras das LER/DORT. Os profissionais de saúde entrevistados também referem a dor osteomuscular como principal queixa apresentada por esses trabalhadores quando acessam os serviços de saúde, o que indica a relação entre tais dores e o processo de trabalho realizado nas agroindústrias.

À ampliação quantitativa da produção com o estabelecimento de altas metas soma-se uma necessidade de melhora qualitativa do trabalho realizado, imposta através do "controle de qualidade". Este é feito por meio da fiscalização constante das atividades realizadas na linha e também resulta na intensificação do trabalho. Nesse sentido, a trabalhadora 14 diz: "Eles (referindo-se aos supervisores) ficam te cobrando, você não pode deixar uma carninha no osso, tem que cuidar, cuidar, cuidar, e eles vão recolhendo o que não está bom, às vezes eles chegam pra ti com aquela bacia cheia de ossos pra refazer, porque cada carne que vai no osso é uma perda, então esse é o pior, não é só desossar, você tem que cuidar aquilo ali”.

A intensificação do trabalho nas agroindústrias também é gerada pelas "diferenças no desempenho dos trabalhadores", tendo em vista as características do processo de trabalho, especialmente as altas metas de produtividade impostas. Essas diferenças no desempenho são ocasionadas por questões como a rotatividade de funcionários nas fábricas e pela presença de trabalhadores doentes na linha de produção.

As agroindústrias da região estudada apresentam altas taxas de "rotatividade" (turnover), como pode ser observado nas informações do Cadastro Geral de Empregados e Desempregados (CAGED) (Ministério do Trabalho e Emprego, 2011), referente às admissões e desligamentos ocorridos no município de Chapecó no período de 2007 a 2011: 
Quadro 5: Frequência das admissões e desligamentos nas ocupações de abatedor e magarefe no município de Chapecó no período de junho de 2007 a junho de 2011

\begin{tabular}{|l|l|l|l|l|l|l|l|l|}
\hline \multirow{2}{*}{$\begin{array}{l}\text { CBO } \\
\text { Frequência* }\end{array}$} & Admissões & \multicolumn{2}{|l|}{ Desligamentos } \\
\cline { 2 - 10 } & Total & $\begin{array}{l}\text { Dispensa } \\
\text { s/ justa } \\
\text { causa }\end{array}$ & $\begin{array}{l}\text { Dispensa } \\
\text { c/ justa } \\
\text { causa }\end{array}$ & $\begin{array}{l}\text { A pedido } \\
\text { empregado }\end{array}$ & $\begin{array}{l}\text { Término } \\
\text { contrato }\end{array}$ & Aposent. & Morte & Total \\
\hline 2o Abatedor & 6.715 & 3.235 & 733 & 2.932 & 380 & 0 & 18 & 7.298 \\
\hline 5- Magarefe & 7.776 & 1.343 & 662 & 3.457 & 603 & 0 & 16 & 6.081 \\
\hline Total & 14.491 & & & & & & Total & 13.379 \\
\hline
\end{tabular}

* CBO - Frequência relaciona-se à ocorrência de rotatividade em um dado período de tempo de acordo com a ocupação definida na Classificação Brasileira de Ocupações (CBO). Nesse sentido, quanto menor a posição numérica, maior a rotatividade. Fonte: CAGED (Ministério do Trabalho e Emprego, 2011)

No quadro acima se observa que entre as vinte ocupações que mais desligaram e mais contrataram no município nos últimos cinco anos, estão as atividades de abatedor ${ }^{14}$ em segundo lugar e magarefe em quinto lugar, ambas comuns às linhas de produção das agroindústrias. $\mathrm{O}$ saldo total de contratações destas ocupações no referido período é de 14.491 , contra 13.379 demissões, o que indica uma dinâmica intensa de trabalhadores entrando e saindo dessas funções. $O$ estudo de Santos (2011) também evidencia o alto turnover no setor, ao mencionar que em alguns períodos uma das agroindústrias de Chapecó chega a ter uma rotatividade de $20 \%$ da força de trabalho em um único mês.

A menção à alta rotatividade nas linhas de produção das agroindústrias foi feita por diferentes sujeitos ao longo da realização desta pesquisa e denota as difíceis condições de trabalho no setor. Essa questão é ilustrada pelo relato da agente de saúde que trabalhou no Serviço Especializado em Engenharia de Segurança e Medicina do Trabalho (SESMT) de uma destas indústrias: "Saía bastante gente, tinha gente que era [como menciona a agente de saúde 2 que também foi técnica de enfermagem] contratada hoje e ficavam dois dias e já saía, pediam as contas, outros trabalhavam algumas horas e saíam, cheguei a ver pessoas que trabalharam duas, três horas e já pediram para ir embora".

Também se observa que aproximadamente 50\% das demissões ocorridas, de acordo com os dados do CAGED dispostos anteriormente, são a pedido do empregado. Nesse sentido, a pesquisa realizada por Arruda e Cunha (2009), em empresa do setor agroindustrial localizada em Chapecó, aponta que essas demissões são motivadas pelas difíceis condições de trabalho desta atividade. Assim, de acordo com as referidas autoras, os funcionários que solicitam desligamento trazem aspectos como "ser um trabalho pesado e ruim", "não se adaptarem ao trabalho em ambientes fechados", "terem medo de trabalhar com facas" e "falta de perspectiva no trabalho", questões que também perpassaram os relatos dos trabalhadores participantes deste estudo.

Além de ser um indicador das dificuldades em relação às condições de trabalho, a alta rotatividade leva à presença constante de funcionários novos e que ainda não dominam a atividade, sobrecarregando os trabalhadores mais experientes, os quais têm que realizar uma quantidade de trabalho maior. A trabalhadora 7 expressa isso quando diz: "Lá era um pauleirão, daí vinha gente nova e as mais velhas que tinham experiência tinham que se lascar, por isso a gente está arrebentado, eu já falei pro chefe, eu estou assim de levar os outros nas costas".

Como pode ser observado no relato anterior, a referida entrevistada relaciona seu problema de saúde a esta intensificação do trabalho na linha, assim como faz a entrevistada 2 que diz: "Não

14 A CBO define a ocupação de Magarefes e afins, código 8485, como aquela que envolve as funções de abatedor, açougueiro, desossador, magarefe e retalhador de carne (MTE, 2011). 
é à toa que eu estou arrebentada, porque eu sempre queria fazer o trabalho direito e sempre faltava gente, sempre tinha gente nova entrando e nós tínhamos que dar conta da meta". Conforme o relato expresso novamente aparece a questão da necessidade dos trabalhadores de uma célula de produção terem de atender à meta imposta para o grupo, a qual não necessariamente é proporcional ao número de trabalhadores presentes, o que aumenta as metas individuais.

Os relatos dos entrevistados apontam que as relações sociolaborais também são impactadas pelo modo como se dá a intensificação do trabalho nessas fábricas, já que muitas vezes a atuação do colega na execução da atividade, mais do que a organização do trabalho, é percebida como fonte da precariedade e do sofrimento do trabalhador que tem que "dar conta" da meta. Nesse sentido, cria-se um ambiente hostil especialmente aos trabalhadores adoecidos, em que exacerbase o individualismo e enfraquece-se a organização coletiva dos trabalhadores, dificultando a resistência a esse modo de produção.

A sobrecarga gerada pelo processo de intensificação do trabalho contribui para o "adoecimento dos trabalhadores" do setor, e este, por sua vez, gera mais intensificação do trabalho, criando nestas fábricas um ciclo vicioso em torno dessa problemática. Assim, os trabalhadores com problemas de saúde não conseguem ter o mesmo desempenho dos demais no cumprimento das metas de produção. Como menciona a trabalhadora 6: "Tem uma que já está lá há três anos, ela disse que quando ela entrou ela fazia bem feitinho e rapidinho e que de uns dois anos para cá ela começou a perder a força do braço, daí ela começa bem rapidinho e conforme vai cansando ela vai deixando, então pra não faltar, não pegar atestado e não ficar com aquela dor enorme ela tem que deixar um pouco."

Como a intensidade do trabalho é ditada pelas metas coletivas de produção, a diferença de desempenho em função do adoecimento também gera uma demanda maior de trabalho aos demais funcionários do setor, como menciona a trabalhadora 2: "Dos nove que deveriam estar na mesa, além dos que faltam sempre tem uma ou duas que estão arrebentadas, tem uma lá que morre a mão dela perde os movimentos, e ela trabalha lá. Só que para eles isso não importa, a meta, o ritmo de trabalho não diminui".

O "quadro funcional incompleto" é outro aspecto relacionado à intensificação do trabalho no setor agroindustrial. Isso está atrelado aos "afastamentos do trabalho" por problemas de saúde, à rotatividade e ao "absenteísmo" ${ }^{15}$ nas empresas do setor. Os afastamentos do trabalho ${ }^{16}$ em função de problemas de saúde são muito frequentes no setor agroindustrial, como pode ser observado pela própria condição dos trabalhadores entrevistados. Desses, treze estavam afastados do trabalho no momento em que concederam a entrevista e um foi afastado posteriormente, enquanto a pesquisa de campo ainda estava sendo realizada.

As informações trazidas por Sardá, Ruiz e Kirtschig (2009) também indicam os altos números de afastamentos nessas indústrias de alimentos. Tomando como base duas entre as três grandes empresas do setor no município esses autores demonstram que em um período de quatro anos houve dois mil, novecentos e oitenta e três afastamentos do trabalho por meio do INSS ${ }^{17}$. A trabalhadora 14 evidencia a problemática dos afastamentos do trabalho, quando menciona: "Sempre faltam duas ou três pessoas na mesa, todos afastados por dor, dor no braço, tem gente que opera os punhos, que dá aquelas bolas sabe, e daí eles fazem cirurgia. Todos com o mesmo problema".

15 O índice de absenteísmo, de acordo com Silva \& Marziale (2000), diz respeito às ausências dos funcionários do trabalho, justificadas ou não.

16 Consideraremos neste elemento de análise apenas os afastamentos do trabalho determinados por atestados médicos em função de acidentes por incapacidade laborativa temporária, que geram auxílio-doença.

17 De acordo com Decreto n 3.048/1999, quando a incapacidade laboral for superior a quinze dias consecutivos, o trabalhador segurado deve ser encaminhado ao INSS para recebimento do auxílio-doença. 
O "absenteísmo" no setor agroindustrial é mencionado na literatura que discute a relação entre este trabalho e a saúde dos trabalhadores, como pode ser observado em Sardá, Ruiz e Kirtschig (2009), Delfani (2007) e Takeda (2010). A falta dos funcionários ao trabalho também é mencionada de maneira recorrente pelos trabalhadores entrevistados e profissionais de saúde, já que geralmente são justificadas por meio de atestados médicos. Como menciona a agente de saúde que também foi técnica de enfermagem em uma destas indústrias: "Tinha bastante atestado, eles levavam direto no ambulatório, era a gente que recebia. Tinha em média cinquenta atestados por turno de trabalho". O que foi observado durante a pesquisa de campo corrobora com o relato desta entrevistada, visto que a emissão de atestados médicos para afastamento do trabalho no município.

Os trabalhadores apontavam sazonalidades em relação ao absenteísmo, o qual parece ser maior em períodos específicos, especialmente no início e final de semana, dias em que o trabalho fica mais difícil pela ausência de funcionários na linha, como menciona o trabalhador 3: "Nos sábados e nas segundas você sofria porque não aparecia muita gente, não iam trabalhar". Essa informação é corroborada pelos profissionais de saúde entrevistados como menciona o médico do Centro Integrado de Saúde da Família (CIS) que relata a busca de atestados pelos trabalhadores do setor: "Perto dos feriados ou segunda-feira são os dias que mais têm atestado, isso acontece direto".

Os relatos de diferentes entrevistados revelam o quanto, diante das faltas de trabalhadores e da impossibilidade de reduzir as metas de produção do grupo, é necessário assumir coletivamente o trabalho excedente, gerando a intensificação, como aponta a entrevistada 1: "Sempre falta gente, daí tem que fazer o serviço de dois. Que nem lá nas caixinhas, se tem quatro e falta um, aí um tem que fazer o serviço do outro, por exemplo se eles precisam dez caixinhas e não têm, eles vão colocar a carne onde? Tem que dar jeito, as caixinhas têm que descer". Os afastamentos do trabalho e o absenteísmo também indicam que, frente à falta de organização coletiva dos trabalhadores para lidar com as adversidades desse contexto laboral, as estratégias de enfrentamento ao sofrimento e ao adoecimento do trabalho são predominantemente individuais e centradas sobre o corpo do trabalhador. Assim, o acesso aos serviços de saúde torna-se o principal meio para lidar com as dificuldades do contexto organizacional.

A intensificação do trabalho cria inúmeras adversidades que comprometem a saúde dos trabalhadores e agravam o quadro de saúde dos trabalhadores já adoecidos, os quais permanecem longos períodos de tempo na linha de produção, expostos a essas condições de trabalho. Assim, inúmeros estudos apontam a relação entre saúde dos trabalhadores e a intensificação do trabalho, dos quais são exemplos Merlo, Vaz, Spode, Elbern, Karkow e Vieira (2003) e Lima (1998), que relacionam esta questão ao aparecimento das LER/DORT. Nesse sentido, também cabe mencionar o estudo de Salanova (2009) sobre a relação entre intensificação do trabalho e saúde, a partir do conceito de estresse laboral. Essa problemática ganha mais relevância na sua interação com outras características deste contexto produtivo como a extensão do tempo de trabalho.

\section{A extensão do tempo de trabalho nas indústrias de alimentos}

A duração do tempo de trabalho em um determinado contexto, segundo Dal Rosso (2006a), é um importante indicador de qualidade de vida, assim como da exploração do trabalho. $\mathrm{Na}$ mesma direção, Assunção e Vilela (2009) apontam que a duração da jornada de trabalho bem como o turno em que esta acontece são considerados indicadores de riscos laborais, já que o período no qual o trabalhador permanece exposto a determinadas condições de trabalho pode influenciar no aparecimento das doenças ocupacionais.

A jornada de trabalho compreende a quantidade de tempo destinada à realização do trabalho, ou, conforme a Constituição Federal (Brasil, 1988), é o espaço de tempo durante o qual 
o empregado deverá prestar serviço ou permanecer à disposição do empregador. Em relação ao trabalhador assalariado, a duração da jornada de trabalho não pode ultrapassar quarenta e quatro horas semanais (Brasil, 1988), as quais segundo o artigo 58 da Consolidação das Leis do Trabalho (CLT) devem ser distribuídas em jornadas diárias de oito horas. Se necessário, esta carga horária pode ser ampliada desde que a jornada de trabalho não exceda 10 horas por dia (Decreto-Lei no 5.452, 1943).

A extensão da jornada de trabalho por meio da realização de horas extras é frequentemente considerada na literatura como um dos principais fatores de risco psicossociais no trabalho. Quando essa condição aparece combinada com a intensificação do trabalho, isso se torna uma das principais vias de acesso ao esgotamento e uma ameaça para o que a Organização Internacional do Trabalho (Boulin et al., 2006) chama de tempo de trabalho decente. Essa tendência emergente é destacada pela literatura como se pode observar nos estudos de Golden e Figart (2001), Hart (2004), International Labour Organization (2001), Lee, S. et al. (2007), Messenger (2004) e OECD (2004).

No caso das agroindústrias da região estudada, a carga horária de trabalho é frequentemente distribuída em cinco dias da semana ${ }^{18}$, o que representa uma jornada de trabalho diária de aproximadamente oito horas e quarenta e oito minutos, salvo os trabalhadores que realizam trabalho noturno ${ }^{19}$. Apesar da delimitação da carga horária mencionada, observamos que há um "prolongamento da jornada de trabalho" no setor. Isso se dá a partir de questões como a realização de "horas extras", o que é mencionado por nove entre os dezessete entrevistados.

A necessidade de realizar horas extras, de acordo com os entrevistados, se dá para atender às demandas de produção, como menciona a trabalhadora 2: "No meu setor sempre passava do horário de ir embora, às vezes dava quarenta minutos, uma hora, às vezes mais. Ou então você se arrebentava pauleando para poder sair no horário, mas eles não deixavam ficar para outro dia".

Segundo Salanova (2009), a realização de horas de trabalho que ultrapassam as horas contratuais pode ser condicionada pelo excesso de trabalho gerado por meio das flutuações da demanda de produtos e serviços do entorno externo, as quais as organizações buscam atender para se manterem rentáveis e competitivas. $\mathrm{O}$ entrevistado 16 ilustra como esse processo ocorre no setor agroindustrial: "tinha vários meses que a fábrica tinha bastante pedido. Então a gente saia dali, o horário normal era meia-noite e quarenta, mas nós saíamos sempre depois das três horas da manhã".

Em estudo acerca da saúde de empregados de frigoríficos na região em que foi realizada a pesquisa, Sardá, Ruiz e Kirtsching (2009) mencionam que as jornadas de trabalho exaustivas são um problema do setor agroindustrial, no qual são comuns horas extras superiores ao limite de dez horas diárias prevista na CLT, inclusive com jornadas de até quatorze horas e vinte e quatro minutos. A entrevistada 3 menciona esta realidade quando diz: "Quantas vezes eu tive que trabalhar das $3 \mathrm{~h} 00 \mathrm{~min}$ da manhã até as $15 \mathrm{~h} 00 \mathrm{~min}$ da tarde quando tinha muito serviço. Era difícil, porque eu tinha que ficar muito tempo fora de casa".

Reconhecendo esta problemática, o Ministério Público do Trabalho, em Termo de Ajuste de Conduta aplicado a uma empresa do município estudado, determinou que ela se abstivesse de “... exigir de seus empregados carga horária de trabalho superior ao permitido legalmente, observada a limitação diária de dez horas" (Ministério Público do Trabalho, 2011, p. 1). Esse controle pontual que começou a ser exercido pela justiça do trabalho em relação às horas extras aparece referido

18 Vale destacar que em períodos de aumento da produção é comum as agroindústrias solicitarem a realização de horas extras aos sábados.

19 De acordo com a CLT, artigo 73, $\S 1^{\circ}$, a hora do trabalho noturno é computada como sendo de 52 minutos e 30 segundos (Decreto-Lei no 5.452, 1943). 
pelos trabalhadores desta empresa. "No começo nós fazíamos muita hora extra, mas ultimamente não estamos mais fazendo porque foi proibido" (trabalhador 5).

A ampliação da jornada de trabalho pela realização de horas além das previstas no contrato de trabalho ocorre também devido à não consideração do "período de troca de roupa" e preparação para entrar nos setores, como aponta a trabalhadora 2: "Sabia que a empresa X não considera o tempo que eles levam para se trocar? Aqui na empresa Y, eles também não pagavam a troca de roupa, diziam que era um período de tolerância. Mas aí tinha muita gente indo pra justiça, então, agora fazem dois anos que nós assinamos um papel dizendo que eles pagam, mas continua a mesma coisa que antes, só que agora o pessoal não pode cobrar na justiça”.

O relato da trabalhadora chama a atenção por indicar que as empresas burlariam a legislação trabalhista para não reconhecerem este período de troca de roupa como tempo de trabalho. O apontado pela entrevistada é corroborado pelas medidas de regularização propostas pelo Ministério Público do Trabalho para uma indústria do setor, em que está disposto que deve ser computado "o tempo destinado à troca de uniformes como de efetiva jornada, nos moldes do art. 4, da CLT" (Ministério Público do Trabalho, 2011, p. 3).

Outro aspecto mais recente que se caracteriza como um alargamento da jornada de trabalhoé o "deslocamento de trabalhadores de outras cidades" da região por longas distâncias para trabalhar nos frigoríficos, devido às dificuldades dessas empresas em completar o quadro de pessoal, como afirma o trabalhador 17: "...é que hoje eles vão buscar os caras para trabalhar em outras cidades, [...] tem gente que passa cinco horas por dia dentro do ônibus”. Essa questão foi reconhecida pela Justiça do Trabalho no município de Chapecó, ao determinar que as empresas remunerassem as horas de deslocamento de empregados contratados em outras localidades, considerando-as horas extras (Ministério Público do Trabalho, 2011).

A forma das agroindústrias gerirem os intervalos dos trabalhadores é outra dificuldade mencionada pelos entrevistados de maneira recorrente. Neste sentido, doze trabalhadores fazem menção ao fato de que os "intervalos obrigatórios" não podem ser cumpridos de maneira adequada pela grande demanda de trabalho. Nesse sentido, a trabalhadora 5 diz: "Quando a gente ganhava show $^{20}$ em cima da mesa, não podia nem lanchar porque depois quando voltava era trabalho dobrado, então tinha que aproveitar o momento que parava pra tirar o atraso".

Alguns trabalhadores também mencionaram que eram pressionados pelos supervisores a encurtar os intervalos, como cita o entrevistado 15: "A gente tinha 45 minutos para almoçar, mas o chefe dizia, voltem em meia hora, porque tem muita coisa para fazer". Essa questão vai ao encontro do que menciona o relatório de fiscalização do Ministério Público do Trabalho em relação a uma agroindústria do município, em que é referenciado o não cumprimento do período obrigatório de intervalos para os funcionários durante o ano de 2007 (Ministério Público do Trabalho, 2008).

Uma das características do trabalho da linha de produção é a necessidade de os trabalhadores ter de permanecer na fábrica durante os "intervalos intrajornada", o que alarga o tempo de permanência na empresa. A impossibilidade de sair se deve ao isolamento dos setores devido ao controle de qualidade, como diz uma enfermeira do CIS: "Tenho um familiar que trabalha em uma agroindústria, mas nas máquinas, então ele não fica todo o tempo na produção, ele pode sair no período de intervalo, pode usar o celular. Mas quem trabalha na linha é bem pesado, eles não podem fazer essas coisas, [...] eles têm que continuar ali dentro, por exemplo, quem está sujo não pode ir para um ambiente limpo e vice-versa" (Enfermeira 2).

Vários trabalhadores participantes da pesquisa mencionaram vivência de mal-estar por permanecerem longos períodos de tempo dentro da fábrica, aspecto agravado pelas condições

20 A expressão show é utilizada com frequência pelos trabalhadores das agroindústrias para indicar o trabalho que não conseguem realizar, que é representado, por exemplo, pelas coxas de frango que não são desossadas e acumulam ao lado do trabalhador ao longo da jornada. 
do ambiente físico. Cabe destacar que uma das características destas linhas de produção é sua iluminação artificial sendo que as janelas, de acordo com os entrevistados, ficam a grande altura e são pequenas, não permitindo visualizar o exterior, aumentando a sensação de confinamento. Nesse sentido, a trabalhadora 9 menciona: "Me dá pavor passar na frente do frigorífico e lembrar que eu poderia estar lá dentro. Aquele ambiente fechado, eu tenho a impressão de que estou sufocando, de que estou apertada, me dá ânsia de vômito, vontade de desmaiar, sabe? A gente não vê a luz do dia, sempre entra de madrugada e depois que você entra, você não vê o dia". A trabalhadora 6 também menciona essa dificuldade, quando diz: "Eu acho muito fechado ali, você entrou parece que é noite, só vai ver o dia quando sair de lá, e a gente fica o dia todo lá dentro, então aquele lugar vai te ansiando, vai te deixando nervoso".

O "trabalho em turnos e noturno" também oferece riscos à saúde dos trabalhadores das agroindústrias. Como forma de otimizar os meios de produção, como espaço físico e equipamentos, as indústrias de alimentos da região funcionam durante vinte e quatro horas por dia, organizando a jornada de trabalho dos seus funcionários em turnos fixos distintos. Esses turnos, frequentemente, implicam em trabalho noturno, como afirma a trabalhadora 13: "Eu começava às $03 \mathrm{~h} 00 \mathrm{~min}$ da manhã e trabalhava até as $12 \mathrm{~h} 10 \mathrm{~min}$, daí eu tinha que levantar às $02 \mathrm{~h} 00 \mathrm{~min}$ da manhã para pegar o ônibus às $2 \mathrm{~h} 30 \mathrm{~min}$ ". Da mesma forma, quatorze trabalhadores participantes da pesquisa mencionaram realizar ou já ter realizado trabalho noturno nas indústrias durante a trajetória de trabalho, o qual geralmente representa apenas uma parte da jornada laboral.

Em relação ao trabalho fixo no turno noturno, emergiram nos relatos dos trabalhadores as "dificuldades em relação ao sono", especialmente para aqueles que iniciam a jornada de trabalho demasiadamente cedo, como menciona a trabalhadora 13: "A noite que eu mais dormia, eu dormia quatro horas e eu chegava em casa do trabalho, eu não conseguia dormir. E daí eu estava tomando remédio, mas mesmo com o remédio eu não dormia. Foi assim um ano e pouco, eu me sentia supercansada, meu olho estava sempre vermelho e estava sempre muito nervosa". Em relação ao trabalho realizado em turno noturno vale apontar que estudos como os de Régis Filho (2002), Rios, Barbosa e Belasco (2010), Vargas e Dias (2011) reconhecem a existência de relações entre tal turno e danos físicos e psíquicos nos trabalhadores, como manifestações agudas de insônia, transtornos de humor, depressão entre outros, os quais vão ao encontro da situação relatada pela trabalhadora entrevistada que estava afastada com o diagnóstico de depressão.

As dificuldades em relação ao tempo e qualidade do sono daqueles que trabalham em turno noturno no setor, também são mencionadas por Sato e Lacaz (2000). Estes autores associam esse horário de trabalho com o aparecimento de enfermidades gastrintestinais e problemas emocionais como ansiedade e depressão. Nesse sentido, um médico do CIS menciona: "Muitos trabalhadores da agroindústria vêm com quadros depressivos, mas a gente sabe que isso tem relação com eles trabalharem à noite, então eles não conseguem dormir direito, não têm uma boa qualidade de sono, daí eles vêm querem atestado, querem remédio, mas a gente sabe que o que resolveria seria trocar o turno" (Notas diário de campo).

Cabe destacar que as situações de sofrimento psíquico e adoecimento mental relacionadas ao trabalho nesse setor produtivo, apesar de menos evidenciadas nos diagnósticos de afastamento do trabalho, foram muito mencionadas nesta pesquisa, tanto no relato dos profissionais de saúde quanto dos trabalhadores entrevistados. Nesse sentido, foram destacadas queixas como irritabilidade, ansiedade, sentimentos de tristeza e medo do futuro e, quando reconhecida uma patologia, essa frequentemente era denominada como depressão. Sendo assim, pesquisa encomendada pelo Ministério Público do Trabalho sobre o perfil dos agravos que acometem afastados do trabalho no estado de Santa Catarina, indica que o índice de transtornos depressivos nos funcionários das indústrias de abate e processamento de carnes é 341\% maior do que em outras atividades econômicas (Procuradoria Regional do Trabalho, 2013). Também se deve salientar que assim como acontece com as dores osteomusculares, a manifestação 
do sofrimento psíquico oriundo do trabalho vira demanda para o setor de saúde que intervém sobre o corpo do trabalhador, em vez de fazê-lo na organização do trabalho.

O tempo de trabalho dentro da fábrica também determina a vida fora dela, como afirmam Batista e Codo (2003), pois as longas jornadas laborais e o trabalho em turnos e noturno têm impactos na "conciliação trabalho-família". Nesse sentido, a principal questão mencionada pelos entrevistados foi a falta de tempo para ficar com os familiares como diz a trabalhadora 3: "Às vezes havia dois dias que eu não via as minhas filhas, porque quando tinha muito serviço ficava na fábrica até mais tarde, daí chegava em casa e ia dormir. Eu também não via a hora de chegar o sábado, anoitecer para cair na cama e dormir, eu sempre estava tão cansada que não tinha como sair. Por isso a gente deixa a família muito de lado".

O tempo da produção, como afirma Hassard (2009), é o tempo principal, aquele ao qual os outros tempos da vida estão condicionados. Estes últimos devem encontrar seus lugares nas sobras do primeiro. Assim, a convivência familiar é marginalizada em detrimento das necessidades da produção. Por outro lado, os diferentes turnos dessas indústrias também possibilitam a alguns trabalhadores entrevistados dividir o cuidado dos filhos entre o casal, o que também facilita a organização familiar, como menciona a entrevistada 10: "Meu marido cuida do meu filho de manhã, de tarde ele vai para a escola e à noite eu fico com ele, então a gente consegue se dividir". No entanto, a mesma entrevistada conta que a dificuldade em ter tempo para o casal devido aos horários de trabalho influencia na relação conjugal: "Uma época eu me separei do meu marido, é que nós praticamente não nos encontrávamos e daí quando nos encontrávamos só brigávamos. (Entrevistadora) Por que não se encontravam? Por causa do trabalho, porque eu começo a trabalhar no frigorífico às 5 h00 min da manhã até as $15 \mathrm{~h} 00 \mathrm{~min}$ da tarde e ele trabalha lá das 18 h00 min até as 3 h00 min da madrugada. Então a gente quase não se via".

Um médico do CIS também mencionou que dificuldades na conciliação trabalho-família devido aos turnos e as longas jornadas são um aspecto presente nas demandas apresentadas por esses trabalhadores no serviço de saúde. Quando questionado sobre como essa dificuldade se traduz em queixas no Centro de Saúde o médico entrevistado responde: "A gente observa aspectos como humor depressivo, e também têm aparecido dificuldades em relação à sexualidade, por exemplo, os homens têm trazido muito a questão da dificuldade de ereção ou ejaculação precoce e as mulheres mencionam a dificuldade em ter orgasmo. Eu observo que na maioria das vezes está relacionado à ansiedade".

A partir das questões apontadas observamos o quanto a forma de gerir o tempo de trabalho tem gerado a ampliação da jornada laboral, aspecto evidenciado pelos relatos dos trabalhadores entrevistados e corroborado pelas ações que têm sido promovidas pelo Ministério Público do Trabalho junto ao setor. Essas intervenções ainda têm caráter pontual e são suscetíveis de ser burladas pelas indústrias, face ao imperativo da produtividade.

\section{Considerações finais}

Como já destacado na introdução deste trabalho, as atividades laborais realizadas nas indústrias de abate e processamento de carnes e o adoecimento dos trabalhadores já são amplamente reconhecidas e estudadas. No entanto, os altos índices de adoecimento e afastamento dos trabalhadores do setor agroindustrial na região estudada, bem como a ocorrência de agravos como a depressão, em proporção muitas vezes maior que em outros setores produtivos, chamam a atenção para a necessidade de continuar investigando os aspectos que determinam a precariedade e os riscos laborais desse contexto produtivo. A isso soma-se a recente expansão do setor e o grande número de trabalhadores vinculados a ele no país. 
Por meio deste estudo observou-se que apesar das tentativas de fiscalização e regulamentação das atividades laborais no setor agroindustrial, vem ocorrendo um processo de intensificação e prolongamento da jornada de trabalho nesse contexto, aspectos que marcam as principais características desse trabalho na região estudada. Nesse sentido, se destacou uma estreita relação entre a atividade produtiva nas indústrias de abate e processamento de carnes e a saúde dos trabalhadores do setor que fazem uso dos serviços de saúde na região estudada.

O contexto laboral no setor agroindustrial é marcado pelos diferentes dispositivos de controle do trabalho, com vistas à produtividade em que se observa uma ordem definida principalmente em termos econômicos, como afirma Bauman (2004). Esta permite ao setor agroindustrial tornarse competitivo e se expandir ganhando relevância na produção industrial brasileira e global, tornando-se a base da economia da região estudada.

Por meio dos relatos dos trabalhadores, foram identificados diversos elementos que caracterizam um sistema produtivo organizado para obter o desempenho máximo dos trabalhadores na linha, mesmo que isso se dê à custa de um trabalho que traz danos à saúde dos trabalhadores. Um desses elementos se refere ao processo de intensificação do trabalho nas agroindústrias, o qual não é um fenômeno isolado e acompanha as tendências dos contextos laborais atuais.

As características do processo de trabalho no setor revelam um exercício de poder centrado no corpo máquina, como menciona Foucault (2005), em que por meio do seu adestramento e ampliação de suas aptidões, consegue-se maximizar o desempenho dos trabalhadores. Mas nas agroindústrias a intensificação do trabalho é potencializada por aspectos como: as diferenças entre os desempenhos dos trabalhadores, face à alta rotatividade e ao adoecimento, e pelos quadros funcionais incompletos devido aos afastamentos do trabalho e ao absenteísmo. Essas dificuldades ocorrem sem que se reduzam as metas de produção, de forma que o trabalho realizado seja mais compatível com a capacidade dos trabalhadores.

A intensificação do trabalho, de acordo com Salanova (2009), se manifesta principalmente por meio do alto ritmo de trabalho e da dificuldade em terminar as tarefas no tempo preestabelecido. Nesse sentido, a palavra mais mencionada pelos entrevistados ao falar de seu trabalho na fábrica foi rapidez, sendo que a grande velocidade com que o trabalho tem de ser realizado certamente é a característica mais marcante das atividades neste setor produtivo.

A maximização do desempenho nestes contextos produtivos também está relacionada aos modos de gerir o tempos de trabalho no interior das indústrias, em que se observa um prolongamento da jornada laboral devido à realização de horas extras. Este prolongamento ocorre ainda em função da não consideração do período para troca de roupas, ao tempo de deslocamento de trabalhadores de outros municípios, da não realização de intervalos obrigatórios bem como devido à necessidade de permanecer dentro da fábrica durante os intervalos intrajornada.

Esses modos de gerir o tempo de trabalho aumentam o período de exposição dos trabalhadores aos riscos inerentes às atividades do setor, bem como influenciam de forma negativa os outros tempos da vida, submetendo-os aos tempos da fábrica. Na mesma direção, o trabalho em turnos e noturno, característico dessas agroindústrias que funcionam 24 horas por dia, dificulta a conciliação trabalho-família, bem como se mostra relacionado às alterações do sono nos trabalhadores usuários dos serviços de saúde.

A forma como se organizam e funcionam estes contextos laborais produzem grande demanda dos trabalhadores do setor por assistência à saúde. Nesse sentido, os problemas oriundos do trabalho, que não têm espaços para ser discutidos e resolvidos neste, assumem a característica de problema individual do trabalhador usuário e se constituem em demandas para a clínica médica nos serviços públicos e privados de saúde. Assim, ao assumir essas demandas por assistência à saúde sem intervir nas condições de trabalho, os serviços de saúde, públicos e privados, também contribuem para a manutenção desse modo de produção adoecedor. 
Em face das questões discutidas, conclui-se que as iniciativas de avançar na regulamentação dos riscos do trabalho no setor agroindustrial são importantes. No entanto, as ações nesse sentido não podem se limitar ao âmbito jurídico-legal, o que é evidenciado pelas formas com as quais são burladas as normas existentes. Assim, a efetiva melhora das condições de trabalho neste setor implica também em um amplo debate com a participação de diferentes atores sociais como os trabalhadores, as organizações sindicais e os distintos serviços do setor de saúde que desenvolvem ações voltadas à saúde do trabalhador.

\section{Referências}

Antunes, R. (2003). Os sentidos do trabalho: ensaio sobre a afirmação e a negação do trabalho. São Paulo: Boitempo.

Araújo, C. G. \& Gosling, M. (2008). Gestão de acidentes de trabalho em uma empresa frigorífica: um estudo de caso. Pretexto, 9(1), 81-94.

Arruda, Z. \& Cunha, D. (2009). Causas e estratégias de enfrentamento da rotatividade numa agroindústria no município de Chapecó - SC. Trabalho de Conclusão do Curso de Psicologia, UNOCHAPECÓ, Chapecó/SC.

Assunção, A. A. \& Vilela, L. V. O. (2009). Lesões por esforços repetitivos: Guia para profissionais de saúde. Piracicaba: Centro de Referência em Saúde do Trabalhador - CEREST.

Batista, A. S. \& Codo, W. (2003). O trabalho e o tempo. In. M. G. Jacques \& W. Codo (Orgs.). Saúde Mental E Trabalho: Leituras. (2a ed.) (pp. 401-420). Petrópolis: Vozes.

Bauman, Z. (2004). Modernidade líquida. Rio de Janeiro: Zahar.

Boulin, J.-Y., Lallement, M., Messenger, J. C. \& Michon, F. (Eds.) (2006). Decent Working Time. New trends, new Issues. Geneva: International Labour Office.

Brasil/OPAS. (2001). Doenças relacionadas ao trabalho: Manual de procedimentos para os serviços de saúde. Ministério da Saúde do Brasil, Organização Pan-Americana da Saúde no Brasil; organizado por Elizabeth Costa Dias, Brasília: Ministério da Saúde do Brasil.

Braverman, H. (1981). Trabalho e capital monopolista: a degradação do trabalho no século XX. Rio de Janeiro: Zahar.

Castel, R. (1998). As metamorfoses da questão social: uma crônica do salário. Rio de Janeiro: Vozes.

CEPAL/FAO (2009). Perspectivas de la agricultura y del desarrollo rural en las Américas: una mirada hacia América Latina y el Caribe. San José: IICA.

Constituição da República Federativa do Brasil. (1988). Brasília: Senado Federal.

Dalla Costa, A. D. \& Souza-Santos, E. R. (2009). Brasil Foods: a fusão entre Perdigão e Sadia. Economia Eु Tecnologia, 5(17), 165-176.

Dal Rosso, S. (2006a). Jornada de trabalho: duração e intensidade. Ciência e Cultura, 59(4), 31-34.

Dal Rosso, S. (2006b). Intensidade e imaterialidade do trabalho e saúde. Trabalho, Educação e Saúde, 4(1), 65-91.

Delfani, J. C. (2007). Avaliação do perfil antropométrico e análise dinamométrica dos trabalhadores da agroindústria do setor de frigoríficos e abatedouros: o caso Perdigão. Monografia, Programa de Pós-Graduação em Engenharia de Produção, Universidade Tecnológica Federal do Paraná, Ponta Grossa, PR.

Decreto-Lei n. 5.452. (1943, 9 de agosto). Aprova a Consolidação das Leis do Trabalho. Diário Oficial da União, seção 1, Brasília.

Decreto-Lei n. 3.048. (1999, 6 de maio). Aprova o regulamento da Previdência Social, e dá outras providências. Diário Oficial da União, seção 1, Brasília.

Duxbury, L., Lyons, S. \& Higgins, C. (2008). Too Much to do, and Not Enough Time: An Examination of Role Overload. In K. Korabik; D. S. Lero D. L. \& Whitehead; (Eds.). Handbook of Work-Family Integration: Research, Theory, and Best Practices (pp. 125-140). San Diego: Academic Press.

Espíndola, C. J. (1999). As agroindústrias no Brasil: "O caso Sadia". Chapecó, SC: Grifos.

Fairris, D. (2004). Towards a Theory of Work Intensity. Eastern Economic Journal, 30(4), 587-601.

Fernandes, R. C., Assunção, A. A. \& Carvalho, F. M. (2010). Tarefas repetitivas sob pressão temporal: os distúrbios musculoesqueléticos e o trabalho industrial. Ciência E̊ Saúde Coletiva, 15(3), 931-942. 
Intensificação e prolongamento da jornada de trabalho nas indústrias de abate e processamento de carnes...

Foucault, M. (2005). História da sexualidade I: a vontade de saber. (16a ed.). Rio de Janeiro: Edições Graal.

Galinsky, E., Bond, J. T., Kim, S. S., Backon, L., Brownfield, E. \& Sakai, K. (2005). Overwork in America: When the way we work becomes too much, Executive Summary. New York: Families and Work Institute.

Gallie, D. (2005). Work Pressure in Europe 1996-2001: Trends and Determinants. British Journal of Industrial relations, $43(3), 351-75$.

Golden, L. \& Figart, D. (Eds.). (2001). Working time: International trends, theory and policy perspectives. New York: Routledge.

Ghisleni, A. P. \& Merlo, A. C. (2005). Trabalhador contemporâneo e patologias por hipersolicitação. Psicologia: Reflexão e crítica, 18(2), 171-176.

Hart, R. (2004). The economics of overtime working. Cambridge, MA: Cambridge University Press.

Harvey, D. (1992). A condição pós-moderna. São Paulo: Loyola.

Hassard, J. (2009). Tempo de trabalho: Outra dimensão esquecida nas organizações. In J. F. Chanlat (Org.). O indivíduo na organização: dimensões esquecidas (pp. 176-194). Vol. I. São Paulo: Atlas.

IBGE. (2009). Tabela 14: Unidades locais, pessoal ocupado total e assalariado, salários e outras remunerações e salário médio mensal, segundo Municípios de Santa Catarina com 50 mil ou mais habitantes e divisão da classificação de atividades 2009. Dados fornecidos pelo IBGE de Chapecó em formato eletrônico, Rio de Janeiro: IBGE.

International Labour Organization (2001). Reducing decent work deficit. Geneva: International Labour Office.

Lee, S. et al (Dirs.) (2007). Working time around the world. Trends in working hours, laws and policies in a global comparative perspective. Geneva: International Labour Office.

Lima, M. E. A. (1998). A LER no setor bancário. In M. E. A. Lima, J. N. G. Araújo \& F. P. A. Lima (Orgs.). LER: dimensões ergonômicas e psicossociais (pp. 52-107). Belo Horizonte: Healt.

Marx, K. (2002). O Capital: o processo de produção do capital (20a ed). Rio de Janeiro: Civilização Brasileira. (Originalmente publicado em 1867).

Messenger, J. C. (Ed.). (2004). Working time and workers' preferences in industrialized countries: Finding the balance. London: Routledge.

Merlo, A., Vaz, M., Spode, C., Elbern, J., Karkow, A., Vieira, P. (2003). O trabalho entre prazer, sofrimento e adoecimento: a realidade dos portadores de lesões por esforços repetitivos. Psicologia $\mathfrak{G}$ Sociedade, 15(1), 117-136.

Ministério do Trabalho e Emprego. (2004). Minuta de nota técnica: medidas para controle de riscos ocupacionais na indústria de abate e processamento de carnes. Brasília: Ministério do Trabalho e Emprego. Recuperado em 20 de abril, 2013,

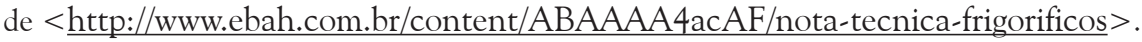

Ministério do Trabalho e Emprego. (2011). Cadastro Geral de Empregados e Desempregados - CAGED. Perfil do município. Brasília: Ministério do Trabalho e Emprego.

Ministério do Trabalho e Emprego. (2013). NR-36 - Segurança e saúde no trabalho em empresas de abate e processamento de carnes e derivados. Portaria MTE n. 555, de 18 de abril de 2013. Brasília: Ministério do Trabalho e Emprego.

Ministério Público do Trabalho. (2008). Relatório de fiscalização a empresa Sadia S/A - Unidade Chapecó, Chapecó, SC. Ministério Público do Trabalho. (2011). Termo de ajuste de Conduta n. 01477/2011. In Procuradoria Regional do trabalho da 12a Região, Ministério do Trabalho (Ed.). Chapecó, SC.

Neli, M. A. (2006). Reestruturação produtiva e saúde do trabalhador: um estudo com os trabalhadores de uma indústria avícola. Dissertação de Mestrado em Ciências Médicas, Programa de Pós-Graduação em Ciências Médicas, Universidade de São Paulo, Ribeirão Preto, SP.

OECD, (2004). Clocking in and clocking out: Recent trends in working hours, Policy Brief. Paris: Organisation for Economic Co-operation and Development, Observer, October.

Picoloto, D., \& Silveira, E. (2008). Prevalência de sintomas osteomusculares e fatores associados em trabalhadores de uma indústria metalúrgica de Canoas - RS. Ciência E Saúde Coletiva, 13(2), 507-516.

Procuradoria Regional do Trabalho no Estado de Santa Catarina. (2013). Notícia publicada em 03/12/2013. Recuperado em 09 de dezembro, 2013, de <http://www.prt12.mpt.mp.br/prt/noticias/2013 12/03 12.php>. 
Reche, D. \& Sugai, M. I. (2008). A influência do capital agroindustrial na distribuição socioespacial urbana do município de Chapecó no sul do Brasil. Actas del X Coloquio Internacional de Geocrítica - Diez años de cambios en el Mundo, en la Geografía y en las Ciencias Sociales 1999-2008, Barcelona: Universidad de Barcelona.

Régis Filho, G. I. (2002). Síndrome da Má-Adaptação ao trabalho em turnos: uma abordagem ergonômica. Revista Produção, 11(2), 69-87.

Resolução n. 196. (1996). Brasília: Conselho Nacional de Saúde.

Rios, K. A., Barbosa, D. A. \& Belasco, A. G. (2010). Evaluation of Quality of Life and Depression in Nursing Technicians and Nursing Assistants. Revista Latino-Americana de Enfermagem, 18(3), 413-420.

Salanova, M. (2009). Psicología de la Salud Ocupacional. Madrid: Editorial Sintesis.

Santos, M. A. (2011). O sofrimento dos Trabalhadores da Agroindústria Sadia S.A. de Chapecó. Dissertação de Mestrado em Serviço Social, Programa de Pós-Graduação em Serviço Social, Universidade Federal de Santa Catarina, Florianópolis.

Sardá Júnior, J. J., Kupek, E., Cruz, R., Bartilotti, C. \& Cherem, A. (2009). Preditores de retorno ao trabalho em uma população de trabalhadores atendidos em um programa de reabilitação profissional. Acta Fisiátrica, 16(2), 81-86.

Sardá Júnior, J. J., Kupek, E. \& Cruz, R. (2009). Preditores biopsicossociais de incapacidade física e depressão em trabalhadores do setor de frigoríficos atendidos em um programa de reabilitação profissional. Acta Fisiátrica, $16(2), 76-80$.

Sardá, S., Ruiz, R. C. \& Kirtschig, G. (2009). Tutela jurídica da saúde dos empregados de frigoríficos: considerações dos serviços públicos. Acta Fisiátrica, 16(2), 59-65.

Sato, L. \& Lacaz, F. A. C. (2000). Cadernos de Saúde do Trabalhador: condições de trabalho e saúde dos trabalhadores(as) do ramo da alimentação. São Paulo: Instituto Nacional de Saúde do Trabalhador.

Serranheira, F., Uva, A. S. \& Espírito-Santo, J. (2009). Estratégia de avaliação do risco de lesões musculoesqueléticas de membros superiores ligadas ao trabalho aplicada na indústria de abate e desmancha de carne em Portugal. Revista Brasileira de Saúde Ocupacional, 34(119), 58-66.

Silva, D. M. P. \& Marziale, M. H. (2000). Absenteísmo de trabalhadores de enfermagem em um hospital universitário. Revista Latino-Americana de Enfermagem, 8(5), 44-51.

Smith, A. (2003). A riqueza das nações. São Paulo: Martins Fontes. (Originalmente publicado em 1776).

Strauss A. \& Corbin, J. (2008). Pesquisa qualitativa: técnicas e procedimentos para o desenvolvimento de teoria fundamentada. (2a ed.). Porto Alegre: Artmed.

Takeda, F. (2010). Configuração ergonômica do trabalho em produção contínua: o caso de ambiente de cortes em abatedouro de frangos. Dissertação de Mestrado em Engenharia de Produção, Programa de Pós-Graduação em Engenharia de Produção, Universidade Tecnológica Federal do Paraná, Ponta Grossa, PR.

Vargas, D. \& Dias, A. P. V. (2011). Prevalência de depressão em trabalhadores de enfermagem de Unidade de Terapia Intensiva: estudo em hospitais de uma cidade do noroeste do Estado São Paulo. Revista Latino-Americana de Enfermagem, 19(5), [09 telas].

\section{Endereço para correspondência}

mapit@unochapeco.edu.br, maria.chalfin@ufsc.br,

Recebido em: 30/04/2013

jmbr.blanch@gmail.com,carmenloom@gmail.com

Revisado em: 18/12/2013

Aprovado em: 13/02/2014 